\title{
Studies of Cranial Capacity between the Ages of 14 - 20 Yrs of Ogidi People of Anambra State, Nigeria.
}

\author{
${ }^{1}$ Ezejindu D.N., ${ }^{1}$ Chinweife K. C., ${ }^{2}$ Ihentuge C.J., ${ }^{2}$ Uloleme G. C. \\ ${ }^{I}$ Department of Anatomy, College of Health Sciences, Nnamdi Azikiwe University, Nnewi \\ ${ }^{2}$ Department of Anatomy, College of Health Sciences, Imo State University, oweri. \\ ${ }_{3}^{3}$ Department of Anatomy, College of Health Sciences, Abia State University, Uturu.
}

\begin{abstract}
The cranial capacity of 527 living subjects (269 males and 268 females) between the ages of 14-20 years old of the Ogidi community of Anambra state of Nigeria were determined. Maximum head width was measured using spreading caliper. Auricular height was measured using auricular head spanner. Maximum head height was measured using measuring tape. Weight was measured using weighing scale. Height was measured using measuring rod in meter.

The results showed the mean and standard deviation of cranial capacity of males; $1410.832 \pm$ $162.405 \mathrm{cc}$ and that of females; $1443.212 \pm 154.283 \mathrm{cc}$. The difference was significant $(p<0.05)$ this investigation shows that cranial capacity is slightly higher in females than in males among adolescent Ogidi's. A positive correlation was found between cranial capacity and age, body weight, body height, and BMI.

This result shows variation from the result obtained by similar studies in the south-East of Caspian Sea boarder (North of Iran), Asia were cranial capacity is higher in males. The difference is due to racial factors.

Keywords: Cranial capacity, Sex, Ogidi community, Body weight, Body height, and BMI.
\end{abstract}

Submitted date 13 June 2013

Accepted Date: 19 June 2013

\section{Introductions}

Cranial capacity is a measure of the volume of the interior of the cranium (skull) of those vertebrates who have both a cranium and a brain.

Cranial capacity which is in close correlation with brain volume reflects racial characteristics. This has been thought to be one of the commonest items in physical anthropological studies ${ }^{13}$.

In the past, several studies have been carried out to estimate the cranial capacity. Most of the studies have been made on dry skull using linear dimensions, packing methods or occasionally, radiological methods. A few studies have been made on living subjects and it exists only in Iranian literature ${ }^{17,18}$. This arouses my interest in studying and estimating the cranial capacity of my local population using living subjects.

Knowledge of the volume of the cranial cavity of either the dry skull or of a living being may be important to the study and comparison of the crania of populations with various fundamental different like geographical, racial, ethnic, dietary etc ${ }^{17,18}$. This information is useful in correlating cranial capacity with other cranial measurements and in studies of primate phylogeny. Medically an analysis of cranial capacity exposes another aspect of growth and development ${ }^{8}$. In clinical practices, it is also used for the study of abnormalities of cranial size and shape.

Cranial capacity can be estimated by measuring the head length, head width and auricular height. It is commonly measured in cubic centimeter ${ }^{19}$.

This present study will aim to estimate the cranial capacity of the living population of the Ogidi community in correlation with the sex, height, body weight, age and BMI.

\section{Subject And Methods}

The study was carried out with 524 living subjects, 269 were males and 268 were females of age 14 20 years old of the Ogidi community of Anambra state of Nigeria. The study was cited in Nnamdi Azikiwe University Nnewi.

The research instruments employed include; measure tape, spreading caliper, carpenters square, transparent ruler, weighing scale, measuring rod.

A random sampling method was used to select the subjects who were observed, interviewed and measured. The measurements were documented and subjected to statistical analysis to get the mean and standard deviation of the study results. 


\section{Results are reported in the table below.}

\section{Results}

The results showed the mean and standard deviation of cranial capacity of males; $1410.832 \pm 162.405 \mathrm{cc}$ and that of females; $1443.212 \pm 154.283 \mathrm{cc}$. The difference was significant $(\mathrm{p}<0.05)$ this investigation shows that cranial capacity is slightly higher in females than in males among adolescent Ogidi's.

Table 1 and 2 displace the number subjects (n) range of age, mean, standard deviation and standard error of mean for both female and male subjects respectively for the study.

It is seen that the average body weight ( $\mathrm{kg}$ ) of Ogidis for female between the age of 14 to 20 have a mean of51.85KG WHILE the male have a mean value of $59.85 \mathrm{~kg}$. Differences in other variables are also shown in table 1 and 2 (see table 1 and 2)

It is seen that the cranial capacity of the female is greater than that of the male.

Female: $1443.212 \pm 154.283$ (Range: $1261.620-1630.660 \mathrm{cc}$ )

Male: $1410,832 \pm 162.405 \mathrm{cc}$ (Range 1243.280-1568.510cc)

There was a significant difference.

Table 3 shows the average age, body weight, body height, body mass index head measurement and cranial capacity of the total population size (male and female combined. It is observed that the result of cranial capacity is above those obtained in Asia (see table 3)

There was a positive correlation between cranial capacity and age, body weight, body height and BMI.

\section{Discussion}

Studies have shown that cranial capacities accompany increasing age from birth as growth progresses. Most growth is achieved in the first 5 years $^{24,25}$. Between the ages of $16-20$ the cranial capacity varies and reaches its peak at age 20. It is thought that Cranial Capacity does not change its size during the rest of the life ${ }^{16}$.

Several investigations have estimated the cranial capacity in the past which indirectly reflect the brain volume. Most of these studies have been made on dry skulls using linear dimensions, packing method or occasionally radiological methods ${ }^{1,18}$.

The cranial capacities of skull belonging to different races have been determined by several authors ${ }^{2,3,4,5,13,17}$. It was reported that the cranial volume in male was $1152.813 \mathrm{SD} 279.16 \mathrm{~cm}^{3}$ and in female: $1117.82 \mathrm{SD} 99.09 \mathrm{~cm}^{3.17}$.

According to ${ }^{13}$ report, the cranial volume was 1470 SD $107 \mathrm{~cm}^{3}$ in male and female $1317 \mathrm{SD} 117 \mathrm{~cm}^{3}$. In native Fars group, male and female were 1369.4SD $142 \mathrm{~cm}^{3}$ and $1215.8 \mathrm{SD} 125 \mathrm{~cm}^{3}$ respectively. Also reported cranial volume of $1548 \mathrm{~cm}^{3}$ in male and $1425 \mathrm{~cm}^{3}$ in female. Studies carried out in native Turkman shows the cranial capacity of $1420.6171 \pm 85.03 \mathrm{cc}$ in males and $1227.2269 \pm 120.712 \mathrm{cc}$ in females. Another study carried out on 366 (226 males and 140 females) healthy university students between 17- 26years at Mugla university Mugla, Turkey using linear dimension of the head shows the cranial capacity and standard deviation in males and females to be $1411.64 \pm 118.9 \mathrm{cc}$ and $1306.96 \pm 162.9 \mathrm{cc}$ respectively.

The results obtained from this research are higher than results obtained from studies in Asia. This is due to fundamental differences like racial, geographic, ethnic, dietary etc ${ }^{11,12,13}$. Therefore, the result obtained from Asia, Europe, and America can be used to estimate the cranial capacity of African especially Ogidis in Nigeria.

\section{Conclussion}

Studies have shown that there is positive correlation between age, BMI and cranial capacity. Several studies have estimated the cranial capacity which indirectly reflects the brain volume in different countries. By comparing this present research with that carried in other parts of the world, it is seen that cranial capacity varies across and within a particular race. There is no standard monogram for all population.

\section{References}

[1]. DEKABAN AS (1977): Table of cranial and orbital measurements, crania volume and derived indexes in males and females from 7 days to 20yrs of age. Ann Neurol. 2:485-491.

[2]. Golalipour M. J, Heydari K. (2006): The Effect of Ethnic factor on Cranial Capacity and Brain Weight of Male Newborns in Northern Iran Eur. J. Anat. 10(2): 49-52.

[3]. GOLALIPOUR MJ and HEYDARI K (2005): Effect of Ethnic Factor on cranial capacity and brain weight of male new born in Northern Iran. Neuro-embryology and aging 3:146-148

[4]. GOLALIPOUR MJ, JAHANSHANI M,HAIDARI K and FARAHANI MR(2003) The shape of head and face in normal male new born in south-east of Caspian sea (iran-Gorgan) J. Anat Soc. India 52:28-31.

[5]. GOLALIPOUR MJ, VAKILI MA and AHMAD POUR M (2000): The relation of weight and height with race, parity, age and kind of delivery of mother. J Qazvin Uni Med Sci 16:58-64)

[6]. GRAU V, ALCANIZ M, JAUN MC, MONSERRA TC. and KNOLL C (2001): Automatic Location of cephalometric landmarks. J. Biomed Inform. 34:146-156

[7]. Gustaton D; Lissner L, Bengtsson C; Bjorkelund C. and Skoog I. (2004): A 24year fellow-up body mass index and cerebral atrophy. Neurology, 63:1876-81. 
Studies Of Cranial Capacity Between The Ages Of 14-20 Yrs Of Ogidi People Of Anambra State,

[8]. Haack, D.C and Meihoff (1971) A method for estimation of cranial capacity from cephalometric Roentgenograms. Am. J. Phys. Antropiol, 34:447-52, 1971.

[9]. HERSKOVITS, M (1930): The Anthropometry of the American Negro. Columbia Press, New York PP350

[10]. Ho K.C, Roessmann, U; Straumfjord, J.V and Monroe G (1980) Analysis of brain weight in relation to sex, race and age Arch. Patrol. Lab Med; 104:635-9.

[11]. HOOTON, EA (1926): A method of racial analysis science, 44:256.

[12]. HOWELLS, W.W (1951): Factors of human physique: American Journal of physical Anthropology 9:159

[13]. HWANG YI, LEE KH, CHOL BY, LEEKS, LEEHY, SIR WS (1995): Student on Korean cranial capacity. J. Korean Med Sci 10:239-242

[14]. JORGENESEN, J.B AND QUAADE (1965): The external cranial capacity American Journal of physical Anthropology 14:661

[15]. AUFMAN, B AND DAVID C J (1972):A method of intracranial volume calculation Investigative Radiology (Philadelphia) 7:533538

[16]. Knutson, B, Momenan, R. and Rowling R.R (2001): Negative Association of neuroticism with brain volume ratio in healthy humans.Bio.psychiatry 50:685-90.

[17]. MANJUNATH KY (2002a): Estimation of cranial volume in dissecting room Cadavers. J. Anat Soc.India, 51:85-91

[18]. MANJUNATH KY (2002b): Estimation of cranial volume in dissecting room cadavers. J. Anat. Soc India, 51:168-172

[19]. McIntyre GT and MISSEY PA (2003): Size and shape measurement in contemporary cephalometrices Eur J. Orthod 25:231-242.

[20]. MIBODI IMA and FARAHANI MR (1996): Study of normal range of anatomical dimensions of one-day old new born by cephalometry. J. Med Council Islamic Republic Iran 14:1-8.

[21]. NAKASHIMA T (1986): Bradycephalization in the head form of school girls in North Kyushu. J. UOEH 8:411-414

[22]. OLIVER RAC (1932):The comparison of abilities of races with special reference to East Africa Med J.

[23]. OKUPE RF, COKER O.O and GBAJUMO S.A.(1984):Assessment of fetal biparietal diameter normal pregnancy by ultrasound in Nigerian women .Brit J . Obstet Gynecol 91:629-632.

[24]. Piatt, J. H. Jr. \& Arguelles, J. H. Reduction cranioplasty for craniocerebral disproportion in infancy: indications and technique. Pediatr. Neurosurg.,16:265-70, 1991.

[25]. Sgouros, S.; Goldin, J. H. \& Hockley, A.D. Intracranial volume change in childhood. J. Neurosurg., 91:610-6, 1999.

Tables of Results

Table 1: The mean, standard deviation, and standard error of Age, body weight, body height BMI, Head length, head width, Auricular Height and Cranial Capacity for female subjects

\begin{tabular}{|l|l|l|l|l|l|l|l|}
\hline PARAMETERS & \multicolumn{1}{|c|}{ NN } & \multicolumn{1}{|c|}{ MIN } & \multicolumn{1}{c|}{ MAX } & \multicolumn{1}{c|}{ MEAN } & \multicolumn{1}{c|}{ SD } & \multicolumn{1}{c|}{ SEM } \\
\hline 1 & AGE(YEARS) & 268 & 14 & 20 & 17 & 0.33 & 0.02 \\
\hline 2 & BODY WEIGHT(KG) & 268 & 44.53 & 56.27 & 51.88 & 0.63 & 0.04 \\
\hline 3 & BODY HEIGHT(CM) & 268 & 158.60 & 170.97 & 165.20 & 0.78 & 0.05 \\
\hline 4 & BMI(KG/M2) & 268 & 17.68 & 20.72 & 19.31 & 0.17 & 0.01 \\
\hline 5 & HEAD LENGTH(MM) & 268 & 152.13 & 211.64 & 183.82 & 3.31 & 0.20 \\
\hline 6 & HEADWIDTH(MM) & 268 & 103.87 & 120.56 & 116.05 & 0.95 & 0.06 \\
\hline 7.AURICULAR HEIGHT(MM) & 268 & 153.67 & 178.80 & 170.97 & 0.92 & 0.06 \\
\hline 8.CRANIAL CAPACITY(CC) & 268 & 980.79 & 1630.61 & 1368.29 & 10.85 & 0.68 \\
\hline
\end{tabular}

Table 2: The mean, standard deviation, and standard error of Age, body weight, body height BMI, Head length, head width, Auricular Height and Cranial Capacity for male subjects

\begin{tabular}{|l|l|l|l|l|l|l|l|}
\hline \multicolumn{2}{|c|}{ PARAMETERS } & N & MIN & MAX & MEAN & SD & SEM \\
\hline 1 & AGE(YEAR) & 269 & 14 & 20 & 17 & 0.32 & 0.02 \\
\hline 2 & BODY WEIGHT(KG) & 269 & 46.00 & 59.85 & 55.40 & 0.79 & 0.05 \\
\hline 3 & BODY HEIGHT(CM) & 269 & 161.25 & 174.00 & 168.46 & 0.70 & 0.04 \\
\hline 4 & BMI(KG/M2 & 269 & 17.70 & 22.65 & 19.77 & 0.15 & 0.01 \\
\hline 5 & HEAD LENGHT(MM) & 269 & 155.30 & 217.05 & 182.54 & 2.82 & 0.17 \\
\hline 6 & HEAD WIDTH(MM) & 269 & 109.50 & 121.28 & 116.150. & 0.70 & 0.04 \\
\hline 7 & $\begin{array}{l}\text { AURICULAR } \\
\text { HEIGHT(MM) }\end{array}$ & 269 & 160.00 & 175.82 & 166.44 & 0.84 & 0.05 \\
\hline 8 & $\begin{array}{l}\text { CRANIAL } \\
\text { CAPACITY(CC) }\end{array}$ & 269 & 1125.70 & 1568.51 & 1350.87 & 27.60 & 1.65 \\
\hline
\end{tabular}

Table 3: The mean, standard deviation, and standard error of Age, body weight, body height BMI, Head length, head width, Auricular Height and Cranial Capacity for both male and female subjects

\begin{tabular}{|l|l|l|l|l|l|l|l|}
\hline PARAMETERS & N & FEMALE & MALE & MEAN & SD & SEM \\
\hline 1 & AGE(YEAR) & 527 & 17 & 17 & 17 & 0.352 & 0.02 \\
\hline 2 & BODY WEIGHT(KG) & 527 & 51.88 & 55.40 & 53.64 & 0.710 & 0.45 \\
\hline 3 & BODY HEIGHT(CM) & 527 & 165.20 & 168.46 & 166.83 & 0.740 & 0.045 \\
\hline 4 & BMI(KG/M2) & 527 & 19.31 & 19.77 & 19.54 & 0.160 & 0.10 \\
\hline 5 & HEAD LENGHT(MM) & 527 & 183.82 & 182.54 & 183.17 & 3.065 & 0.185 \\
\hline 6 & HEAD WIDTH(MM) & 527 & 116.05 & 116.15 & 116.10 & 0.70 & 0.04 \\
\hline
\end{tabular}


Studies Of Cranial Capacity Between The Ages Of 14-20 Yrs Of Ogidi People Of Anambra State,

\begin{tabular}{|l|l|l|l|l|l|l|l|}
\hline 7 & AURICULAR HEIGHT(MM) & 527 & 160.00 & 175.82 & 166.44 & 0.84 & 0.05 \\
\hline 8 & CRANIAL CAPACITY(CC) & 527 & 1125.70 & 1568.51 & 1350.87 & 27.60 & 1.65 \\
\hline
\end{tabular}

Means and standard deviation of cranial capacity were;

Female: $1443.212+154.283$ (Range: $1261.620-1630.660 \mathrm{cc}$ )

Male: $1410.832+162.405$ cc $\{$ Range: $1243.280-1568.510 \mathrm{cc}\}$ There was no significant difference

A positive correlation was found between cranial capacity and age, body weight, body height, and BMI.

Fig 1 - 7. Shows the graphical representation of cranial capacity vs Age, Body Height, Body Weight, and BMI in both male and female

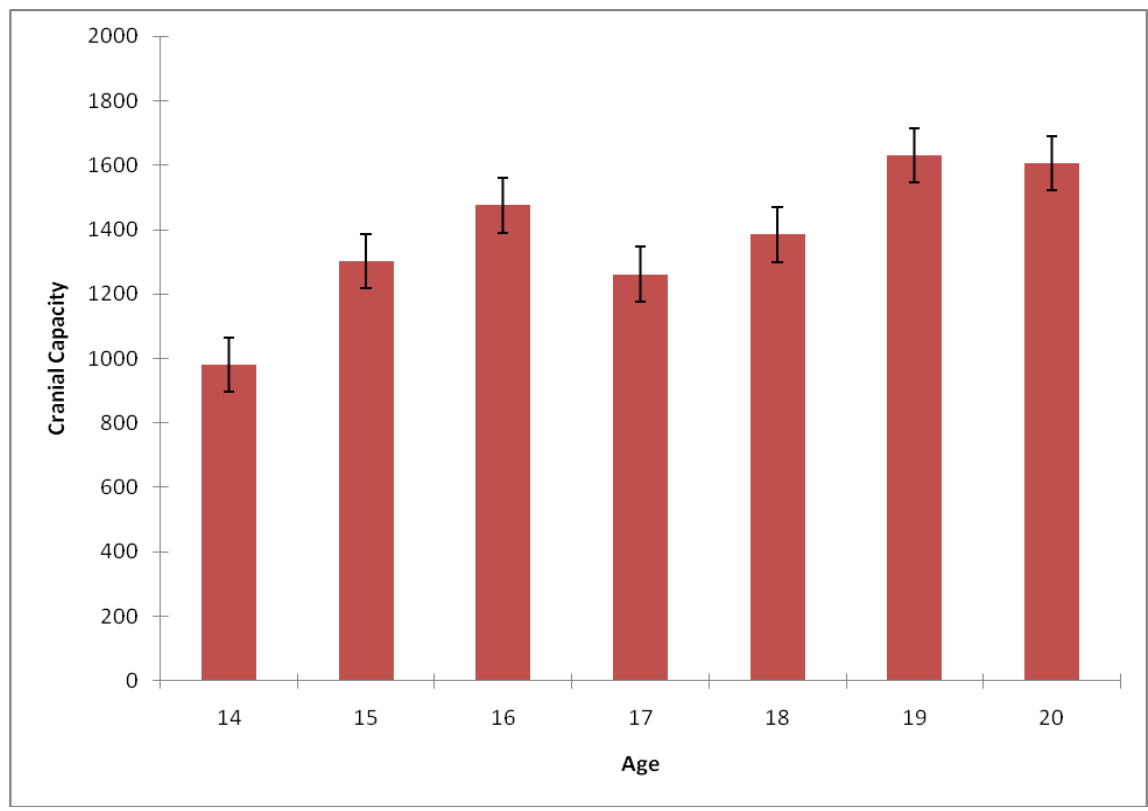

Figure 1: A bar chart representing female cranial capacity vs age.

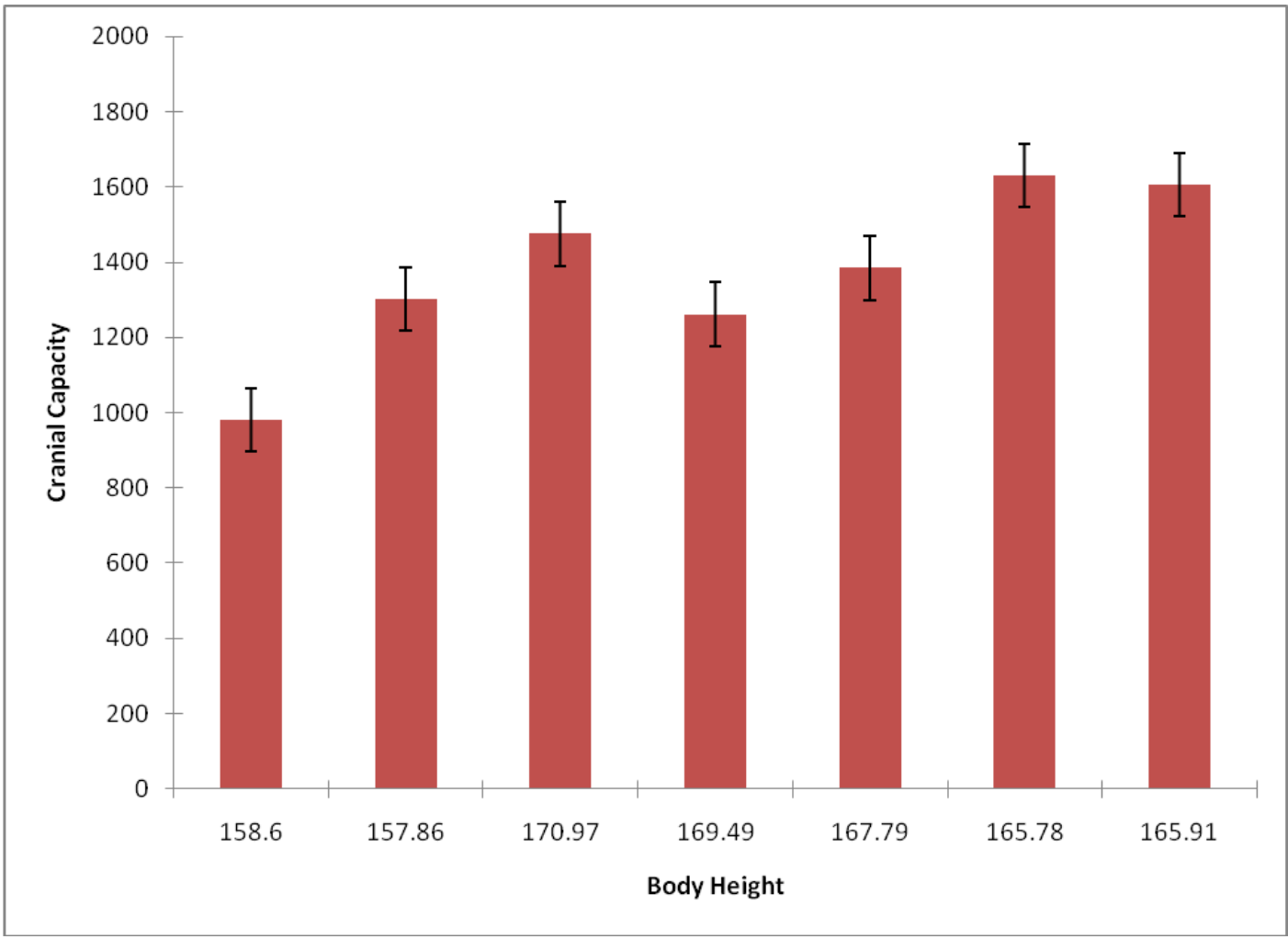

Figure 2: A bar chart representing female cranial capacity vs body height 


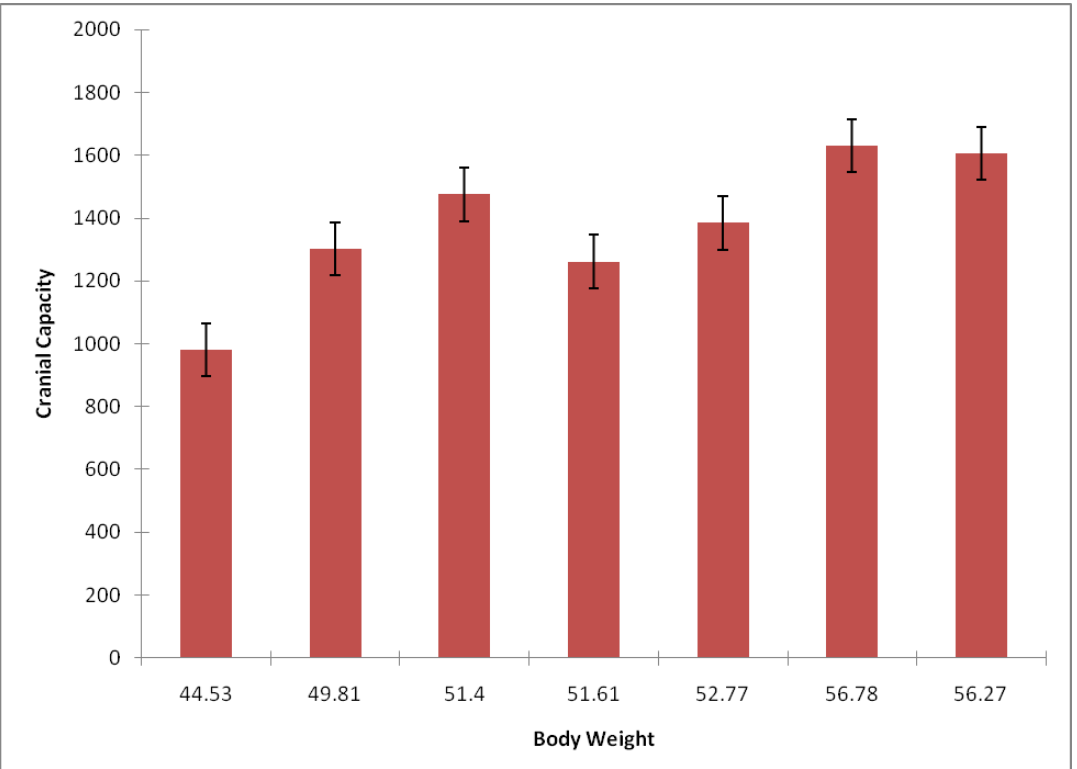

Figure 3: A bar chart representing female cranial capacity vs body weight

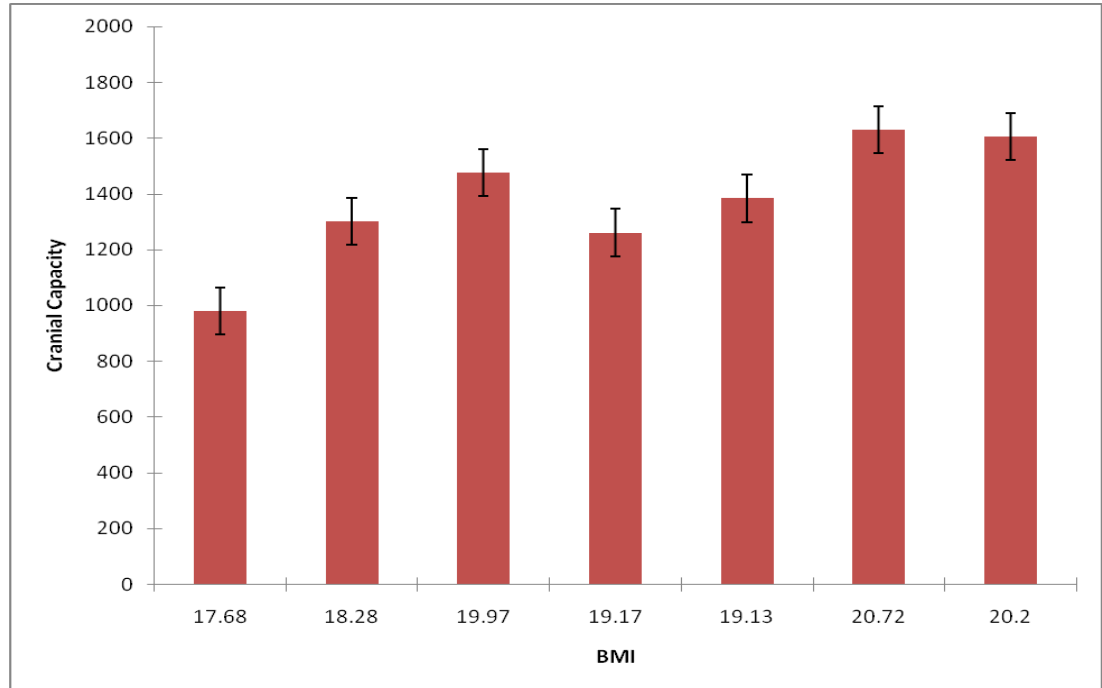

Figure 4. A bar chart representing female cranial capacity vs BMI

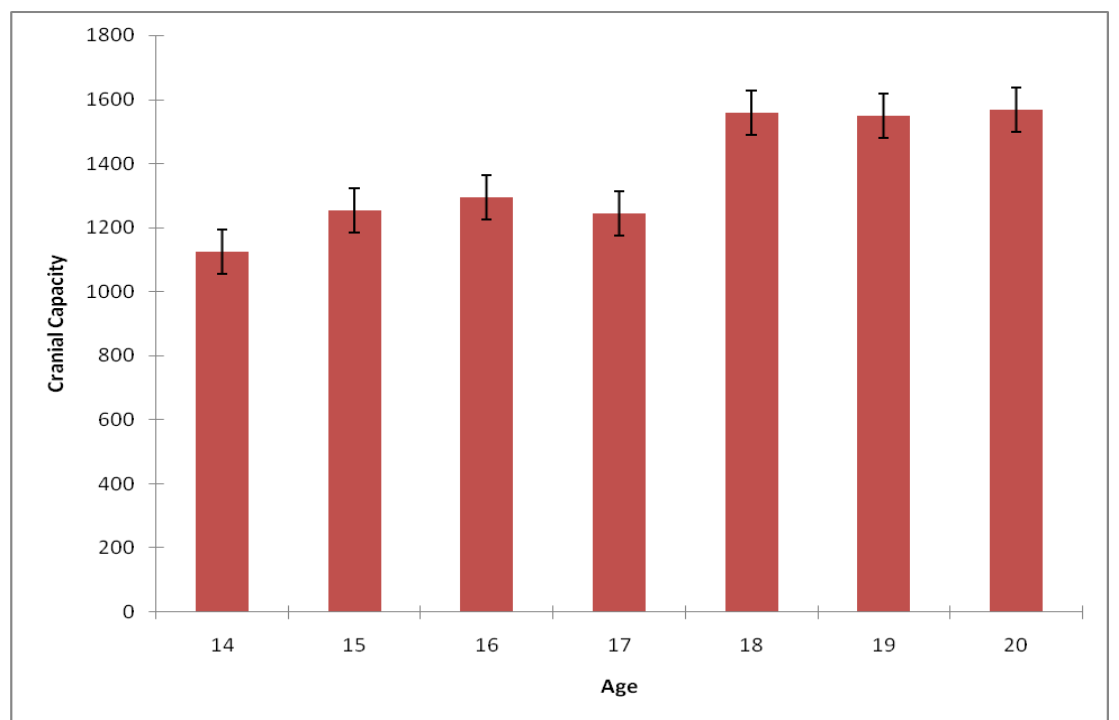

Figure 5: A bar chart representing male cranial capacity vs 


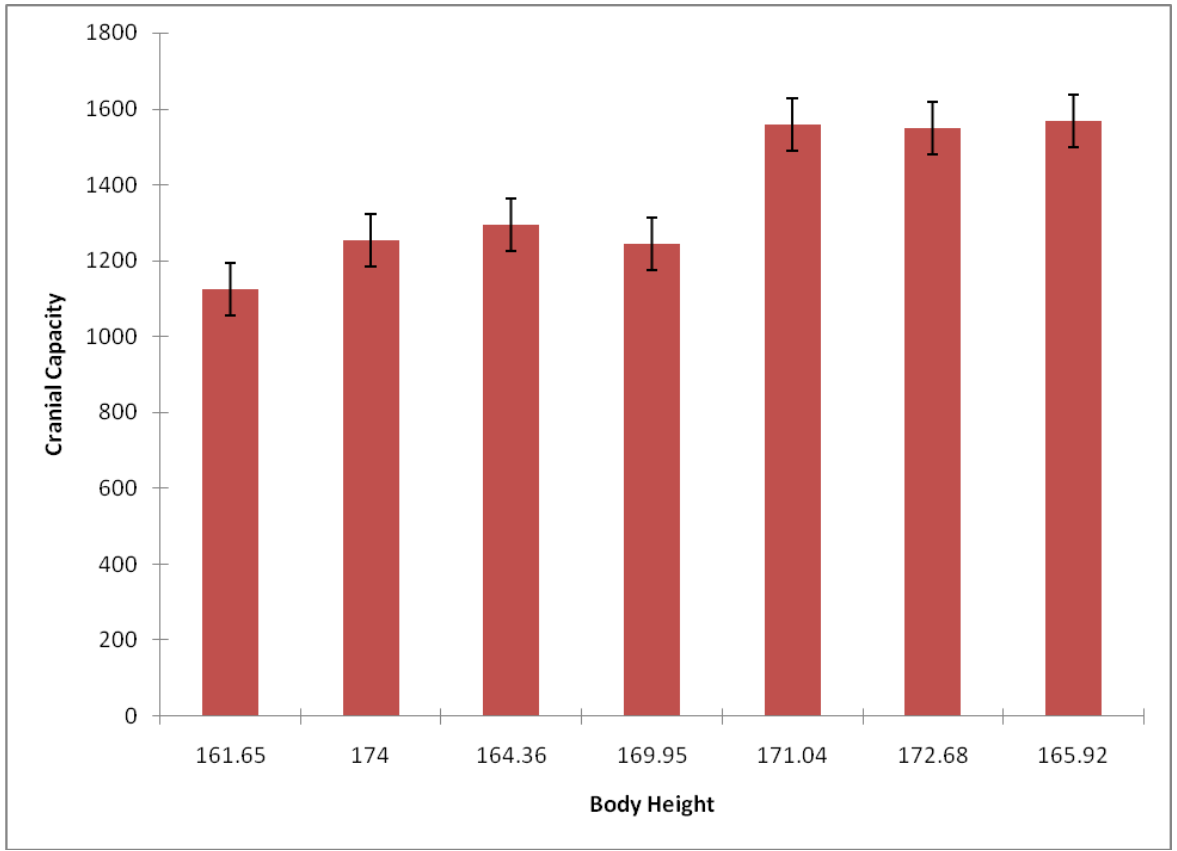

Figure 6: A bar chart representing male cranial capacity vs body height

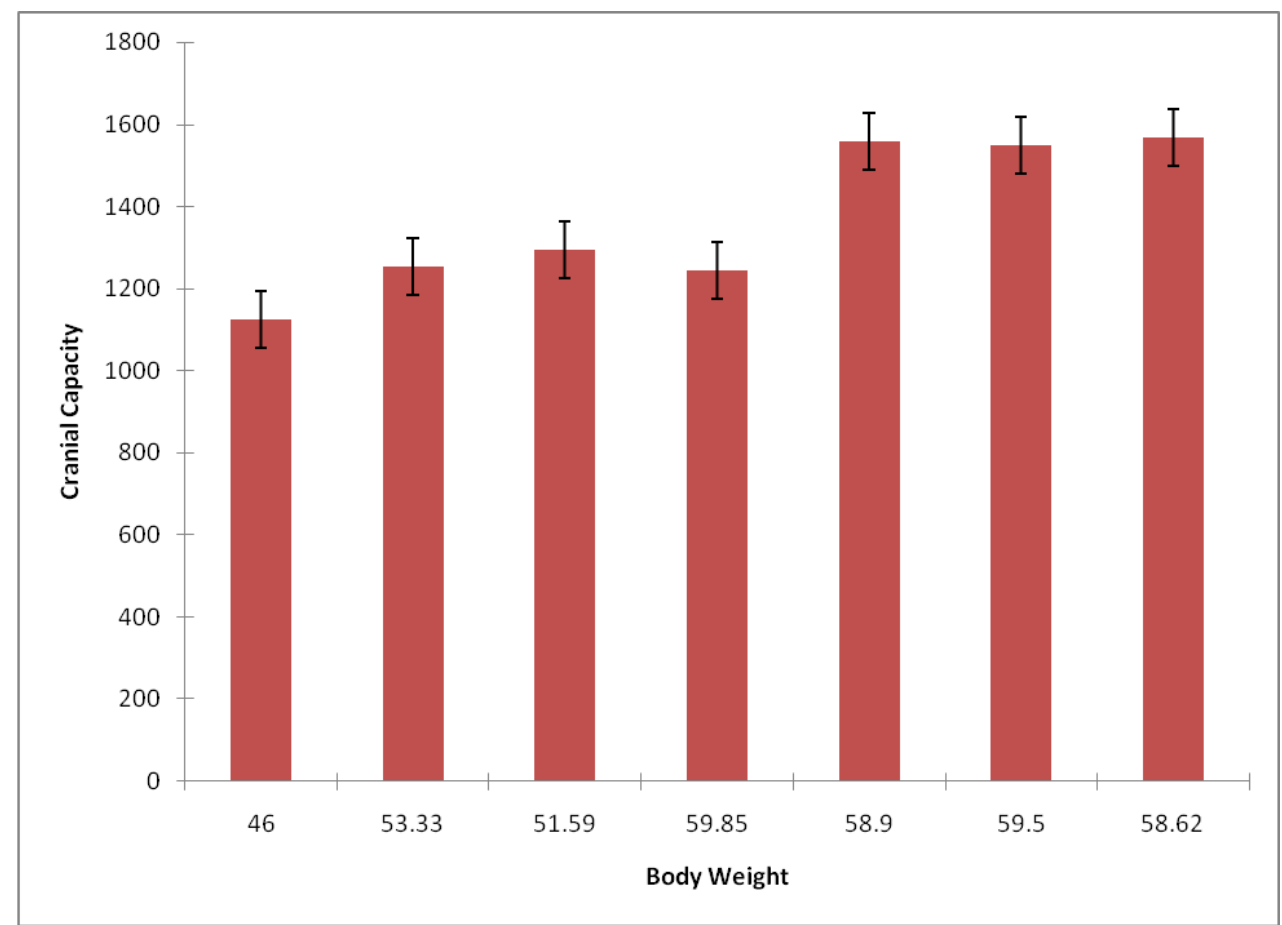

Figure 7: A bar chart representing male cranial capacity vs body weight 